\title{
Care, communication and educational needs of primary care nurses to treat disabled patients
}

\author{
Neree Claes ${ }^{* 1,2}$, Hannelore Storms ${ }^{1}$, Vincent Moermans ${ }^{2}$ \\ ${ }^{1}$ Faculty of Medicine and Life Sciences, University Hasselt, Hasselt, Belgium \\ ${ }^{2}$ vzw Wit-Gele Kruis Limburg, Belgium
}

Received: December 18, 2015

DOI: $10.5430 /$ jnep.v6n7p109
Accepted: February 9, 2016

Online Published: March 16, 2016

\begin{abstract}
Introduction: In the northern part of Belgium, 21,518 of 129,021 disabled patients (DP) were waiting to receive residential care. Due to waiting lists for DP, Belgian government promotes a shift towards primary care. This shift results in specific needs for primary care professionals (general practitioners, primary care nurses [PCN] and informal caregivers). The objective of this research was to detect nursing care, communication and educational needs of PCN to treat their DP and their informal caregivers. Methods: A questionnaire was constructed by a multidisciplinary team of primary care professionals (4 general practitioners and 20 PCN) in different consensus meetings. Disabilities are defined as physical and/or intellectual impairment. The questionnaire was sent electronically to participants. Analysis is performed using SPSS 22.0.

Results: 1547 questionnaires were mailed, $617 \mathrm{PCN}$ responded (response rate $=40 \%$ ). $\mathrm{PCN}$ are delivering care to 16 patients (+/-10) of which 5 DP (+/-6). 408 PCN have contact with at least half of informal caregivers. Most PCN $(n=582)$ report overburdening of informal caregivers due to an overload of tasks $(72 \%)$. Personal hygiene and administering medication are most frequent administered care. Communication with DP and primary health care professionals is evaluated as very good. Most reported educational needs are dealing with behavioral problems (84\%), functional loss (84\%) and acquired brain injury (74\%). There is no significant difference in educational needs of PCN nursing exclusively at home versus at least in residential care facilities.

Conclusion: PCN prefer education on dealing with behavioral problems, which corresponds to previous studies. An educational program can be designed to ensure PCN have necessary skills to ensure high quality care for DP and a reduced overburdening of informal caregivers.
\end{abstract}

Key Words: Education, Primary care, Nursing care, Physical disability, Intellectual disability

\section{INTRODUCTION}

In Belgium, 264,602 disabled patient (DP) are registered, 129,021 of them are living in the northern, Flemish part. ${ }^{[1-3]}$ The care for DP is organized by the Flemish Agency for persons with disabilities, called VAPH ("Vlaams Agentschap voor Personen met een Handicap"). This agency facilitates participation, integration and opportunities for persons with disabilities in all domains of social life in order to achieve maximum autonomy and quality of life for DP. This agency subsidizes residential care facilities and services; assistive aids and customized accommodation to improve the daily life of the DP; personal-assistance budget for disabled persons who prefer living at home. In 2013, 21,518 DP (16\%) were waiting to receive residential care or a personal-assistance

\footnotetext{
*Correspondence: Neree Claes; Email: neree.claes@uhasselt.be; Address: Faculty of Medicine and Life Sciences, University Hasselt, Hasselt, Belgium.
}

Published by Sciedu Press 
budget. Despite efforts of the Flemish government to provide necessary care for DP in a community-setting, there are still long waiting lists for both facilities and personal-assistance budget. ${ }^{[1-3]}$ In the Netherlands, health care for DP is more accessible than in Belgium. Waiting lists are almost nonexisting as is stated in a report: in the beginning of 2014, of the approximately $184,000 \mathrm{DP}, 4,836 \mathrm{DP}(2 \%)$ do not receive care of their choice, only 72 were critically waiting for care. ${ }^{[4-6]}$

Due to the waiting lists, Belgian government promotes a shift towards primary care. Primary care in Belgium is provided by general practitioners, primary care nurses $(\mathrm{PCN})$ and informal caregivers. Deliverance of primary care has shown to have important positive effects on health outcomes and mortality for DP. ${ }^{[7,8]}$ Although primary care is highly accessible in Belgium, this shift to primary care results in specific needs for primary care professionals. Primary care is not organized to adequately respond to this evolution and action has to be taken. Primary care professionals are suddenly confronted with the specific needs of DP and have limited knowledge or experience with nursing care that DP require. To provide DP with the necessary care, it is often needed to rely on informal caregivers. This care is complementary to formal care. ${ }^{[9]}$ The role of informal caregiver can be very demanding. ${ }^{[10-12]}$ To prevent overburdening of the informal caregiver with the care for their family member or friend, the emphasis should always be on formal care.

To assure DP have access to primary care, it is important that health care professionals' needs are addressed. Research shows that primary care providers are often not educated about care for DP, are unaware of the way to react to specific behaviour or do not know how to communicate with DP. ${ }^{[13-17]}$ A lack of knowledge can cause anxiety and PCN might feel overwhelmed and be more reluctant to treat someone with a disability. ${ }^{[16,18]}$ This need for more knowledge is also perceived by some informal caregivers. ${ }^{[19,20]}$ As PCN are the first contact with primary care, it is necessary they feel secure when being consulted by a DP and/or their informal caregiver. ${ }^{[21]}$ Failure to assess the needs of DP, results in restricted access to necessary care for this vulnerable group, possibly leading to a worsening of their health problems. ${ }^{[22]}$

The objective of this research was to detect nursing care, communication and educational needs of PCN to treat their DP and take care of their informal caregivers.

\section{MethodS}

A questionnaire was drawn up by a multidisciplinary team of primary care professionals (4 general practitioners and 20 $\mathrm{PCN}$ ) in different consensus meetings. The questionnaire was made in Qualtrics online survey software and mailed as a hyperlink to the participants. In order to maximize participation, key figures distributed the electronic version of the questionnaire to PCN. Targeted PCN were both PCN who are self-employed and PCN working for a nursing organization. The latter operate in a home care setting, which includes residential care facilities. Response rate of these PCN was checked weekly and reminders were sent to non-responders. Self-employed PCN received one reminder two weeks after the initial mailing.

The objective of this research was to detect nursing care, communication and educational needs of PCN to treat their DP and take care of their informal caregivers. Therefore, following topics were addressed: characteristics of PCN (4 items), DP (6 items) and informal caregivers (8 items); nursing care (10 items), educational needs (18 items) and communication with DP (4 items) and other health care professionals (3 items). Disabilities are defined as a physical and/or intellectual impairment. These can be congenital or non-congenital, for instance: Down syndrome, oxygen deprivation at birth, acquired brain injury due to trauma or to disease, spina bifida, muscular diseases. Sensory disabilities and impairments attributed to the normal ageing process in the elderly are excluded.

Descriptive analysis of data was undertaken using SPSS Statistics 22.0: mean with Standard Deviation is calculated. A case-controlled comparison between PCN working exclusively at home and those at least working in a residential setting was carried out. A Chi-square analysis with 5\% level of significance was performed to compare groups. Respondents with missing values for one or more variables were excluded from the analysis that included those variables.

\section{RESULTS}

\subsection{Primary Care Nurses (PCN), Disabled Patients (DP) and Informal Caregivers}

In total, 1547 questionnaires were mailed, 617 primary care nurses (PCN) responded, representing a response rate of $40 \%$. 146 PCN did not fully complete the questionnaire. Figure 1 shows the age distribution of our respondents. Internal consistency reliability (Cronbach's alpha) of sub-scales: 0.751 (problems experienced by informal caregivers; 5 items), 0.827 (nursing care; 10 items), 0.766 (education about supportive tools and relevant procedures; 8 items).

PCN are on average delivering daily care to 16 patients (+/$10)$, with a mean of 5 DPs $(+/-6)$. The mean distribution of disability is $1 / 3$ physical, $1 / 3$ intellectual and $1 / 3$ mixed disability. $341 \mathrm{PCN}$ take care of DP exclusively at home. $45 \%$ of participated PCN take care of patients at home and 
in residential care facilities: most of these patients are physically disabled. Informal caregivers of DP living at home, are in decreasing order: partners, parents, children, brother/sister and friends. Only 27 PCN have no contact with an informal caregiver and 408 PCN have contact with at least half of the informal caregivers. Most PCN $(n=582)$ report an overburdening of informal caregivers due to following problems: overload of tasks (72\%), acceptance problems of the disability (56\%), difficulties to find suitable care for DP (48\%) and difficulties in their communication with DP (44\%).

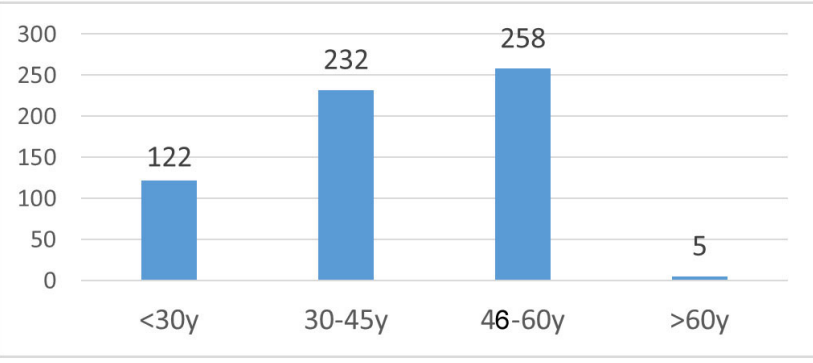

Figure 1. Age distribution of primary care nurses $(n=618)$

\subsection{Nursing care}

In decreasing order, the following clinical problems are raised by DP: physical problems (88\%), medication management $(73 \%)$, mental- and behavioural problems $(70 \%)$, follow-up of nutritional status (malnutrition or obesity) (50\%) and swallowing problems (31\%). Table 1 shows the most frequently provided nursing care for DP at home and in residential care facilities. $96 \%$ of $\mathrm{PCN}$ administer frequently personal hygiene care to DP and the least frequent administered care is the use of a urinary catheter to drain and collect urine from the bladder.

Table 1. Percentage of PCN frequently or seldom nurse this type of care $(n=617)$

\begin{tabular}{lll}
\hline & Frequently & Seldom \\
\hline $\begin{array}{l}\text { Personal hygiene care } \\
\text { Administering medication (+/-injections) } \\
\text { Wound care }\end{array}$ & $96 \%$ & $4 \%$ \\
$\begin{array}{l}\text { 42\% Stoma (gastro-colon-urethra) } \\
\text { 34\% Post-operative }\end{array}$ & $25 \%$ \\
$\begin{array}{l}\text { 24\% Decubitus } \\
\begin{array}{l}\text { Enema administration } \\
\text { Use of a urinary catheter to drain and } \\
\text { collect urine from the bladder }\end{array}\end{array}$ & $55 \%$ & $45 \%$ \\
\hline
\end{tabular}

\subsection{Communication with DP and other health care pro-} fessionals

Communication with DP is evaluated as good to excellent by 93\% ( $\mathrm{n}=436)$ PCNs. Miscommunication is reported by $7 \%$ PCN and is attributed to: low intellectual capacities $(n=23)$, no tools to communicate $(n=18)$ or cultural differences $(n=$ 7). Quality of communication of PCN with primary health care professionals is shown in Figure 2.

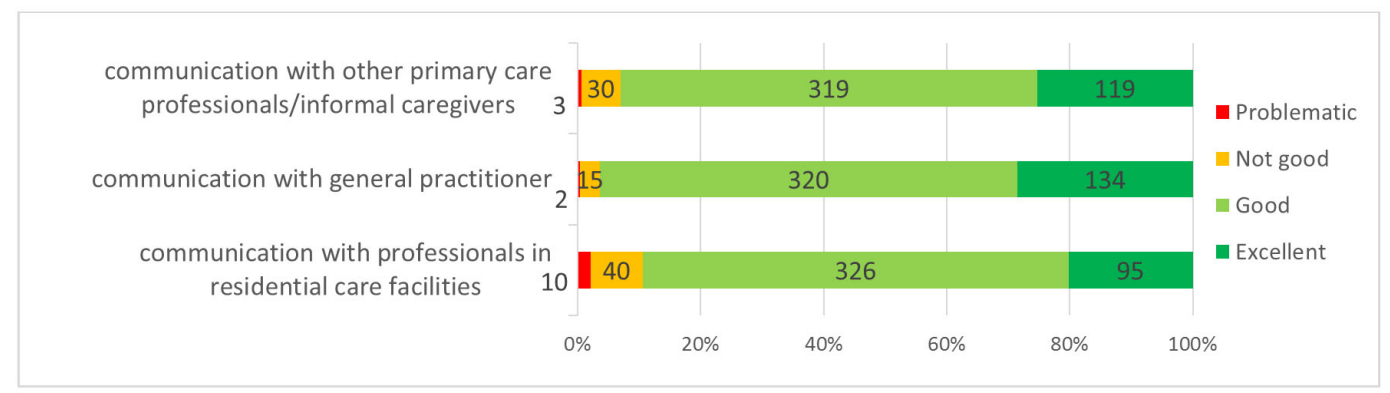

Figure 2. Evaluation of the communication with primary health care professionals $(n=463)$

\subsection{Educational needs}

Most frequently reported educational needs concern: dealing with behavioral problems (84\%), functional loss (84\%) and acquired brain injury (74\%). Table 2 shows the educational needs of PCN (exclusively) at home and in residential care facilities.

Regarding actions resorting under the organization of the Flemish Agency for persons with disabilities (VAPH) unsatisfactory knowledge is reported by a significant number of PCN: $81 \%$ mention a need for education about the personal- assistance budget, $80 \%$ about the procedure for admission in residential care, $73 \%$ about the Flemish Agency for persons with disabilities and $62 \%$ about the existing residential care facilities. There is also inadequate knowledge on supportive tools to improve communication (89\%), living at home (24\%), activities of daily life (23\%) and mobility of DP $(11 \%)$.

\section{Discussion}

Due to the shifting paradigm, primary care services face important challenges in providing DP with the necessary 
health care. Research shows that DP report unmet needs as a result of hampered accessibility. ${ }^{[2-25]}$ DP's needs are often unrecognized because of unawareness or lacking knowledge of health care professionals. ${ }^{[13-16]}$ To ensure best quality of care for DP, health care professionals' needs should be addressed. Therefore, this research examined PCN's nursing care, communication and educational needs, enabling them to treat their DP and to take care of their informal caregivers. Findings demonstrate the need for additional education about ways to deal with behavioral problems and functional loss, as well as the need for more information about measures available to DP (such as communication tools) and knowledge on the role of DP expert organization "VAPH".

Table 2. Educational needs of PCN caring for DP: home-setting $(\mathrm{n}=264)$ versus home \& residential care facilities $(\mathrm{n}=207)$

\begin{tabular}{|c|c|c|c|}
\hline & Home & $\begin{array}{l}\text { Home \& } \\
\text { residential } \\
\text { care }\end{array}$ & $\begin{array}{l}\chi^{2}(1, \mathrm{~N}=471)= \\
\chi^{2} \text {-value, } \\
P \text {-value* }\end{array}$ \\
\hline $\begin{array}{l}\text { Dealing with } \\
\text { behavioural } \\
\text { problems }\end{array}$ & $218(82 \%)$ & $180(86 \%)$ & $0.38, p=.53$ \\
\hline $\begin{array}{l}\text { Dealing with } \\
\text { functional loss }\end{array}$ & $202(76 \%)$ & $172(83 \%)$ & $2.30, p=.130$ \\
\hline $\begin{array}{l}\text { Acquired brain } \\
\text { injury }\end{array}$ & $187(71 \%)$ & 157 (76\%) & $0.60, p=.440$ \\
\hline Muscle diseases & $184(70 \%)$ & $166(80 \%)$ & $0.08, p=.781$ \\
\hline $\begin{array}{l}\text { Muscle rigidity and } \\
\text {-spasticity }\end{array}$ & $168(64 \%)$ & $148(71 \%)$ & $1.02, p=.312$ \\
\hline Epilepsy & $165(62 \%)$ & $146(70 \%)$ & $0.38, p=.535$ \\
\hline Cerebral palsy & $159(60 \%)$ & $130(62 \%)$ & $0.02, p=.893$ \\
\hline $\begin{array}{l}\text { Relational problems } \\
\text { (sexual needs) }\end{array}$ & 147 (55\%) & $134(64 \%)$ & $1.45, p=.228$ \\
\hline $\begin{array}{l}\text { Socio-emotional } \\
\text { age }\end{array}$ & $128(48 \%)$ & $129(62 \%)$ & $2.90, p=.089$ \\
\hline Down syndrome & 119 (45\%) & 135 (65\%) & $3.53, p=.06$ \\
\hline
\end{tabular}

*significance $<.05$

The majority of PCN participating in this study are taking care of DP at home. There was no overrepresentation of PCN caring for DP with a specific type of disability. Moreover, there was no significant difference in educational needs between PCN taking care of DP exclusively in a home-setting, compared to PCN treating DP both at home or in residential care facilities.

As reported by PCN, informal caregivers are overloaded with tasks and need some support in their coping with the disability of their beloved-one, as well as with finding care facilities for DP. As PCN frequently report about their need of additional education on dealing with behavioral problems and functional loss, providing PCN with the necessary skills will not only improve their clinical practices, but will also allow them to give guidance to informal caregivers regarding coping strategies. Presumably, addressing PCN's inadequate knowledge on the role of the Flemish agency for persons with disabilities ("VAPH"), would make them capable to share this knowledge with DP and their informal caregivers and might, if necessary, steer them into the direction of alternative care solutions, while waiting for admission in care facilities of their choice. The usage of alternative, more formal care could decrease the overburdening of these informal caregivers.

Despite difficulties with accessing suitable care, communication between PCN and both health care professionals and DPs is reported to go well. Although communication was not objectively measured, it is reassuring that no problems are reported as (multidisciplinary) health care information exchange is crucial for high quality care. ${ }^{[26-28]}$ Despite the majority of PCN communicating well with DP, miscommunication is mostly attributed to characteristics associated with the disability. This shows the importance of informing PCN accordingly: as DP might have problems understanding and communicating, sometimes as part of their disability, PCN should have clinical knowledge to foresee these obstacles. Moreover, PCN should be trained to employ strategies in order to engage DP in their treatment. ${ }^{[29-31]}$

Focusing on the educational needs, there is no significant difference between PCN who do (not) exclusively treat PD at home. When interpreting these data, it is important to take into account that these 'groups' of PCN were constructed and compared in a case-controlled, retrospective manner. Both groups of PCN prefer additional education about dealing with behavioral problems and with functional loss, followed by information on acquired brain injury (exclusively home) or on muscle diseases (home and residential care facilities). These results are not surprisingly as they correspond with previous research reporting about health care professionals' inadequate clinical knowledge on the specific disability, secondary conditions and associated (to be expected) behavior, as well as insecurities about strategies to respond to DP and their 'peculiar' behavior. ${ }^{[13-18,32-34]}$ As research of Emerson et al. reports, prevalence of challenging behavior varies depending on the study, from $5 \%$ up to $15 \%$ of people with an intellectual disability. ${ }^{[35]}$ Research of van Schrojenstein et al. states a point prevalence of $41 \%$ in people with an intellectual disability with the most prevalent type being problem behavior. ${ }^{[36]}$ This kind of behavior is often categorized as the (only) indicator of a medical problem, although underlying psychiatric problems are more frequently the cause. ${ }^{[36]}$ Unfortunately, Bates et al. also report about nurses lacking knowledge with regard to mental health issues. ${ }^{[37]}$ Consequently, it is likely PCN will come across 'challenging behavior' in their daily practice. Similar findings about diffi- 
cult interaction are presented in research about educational needs of general practitioners ${ }^{[17,33]}$ and of health care professionals working in a hospital setting. ${ }^{[38]}$ Because of the likely confrontation with challenging behavior when working with DP and because of frequently reported inadequate knowledge on coping strategies, the National Institute for Health and Clinical Excellence (NICE) as well as a group of Canadian experts developed guidelines to advise (primary) health care professionals about best care practices for this population. ${ }^{[39,40]}$

\subsection{Limitations}

This study provides insight into the needs of PCN regarding nursing care, communication and educational needs in the care for DP. The questionnaire was validated by a multidisciplinary group of health care professionals working with DP in a primary care setting. Face validity was assessed, as well as Cronbach's alpha for the majority of subscales. Moreover, findings must be interpreted prudently, as selection and response bias is possible. Findings are limited to the needs of PCN working in one geographic area. Research was intended to collect valuable, in-depth information from this specific group: consequently, maximum participation of this one organisation (employing about 1,500 nurses) was pursued. Although it might have reduced selection bias, participants were not randomized because of the descriptive, explorative scope of the research. The objective of this research is not to generalize, although this would - to some extent - be justified, as certain needs reported in this research are similar to previous studies. ${ }^{[16,18]}$ Despite the questionnaire being distributed broadly in the targeted region, there is potential response bias if only PCN with a specific interest participated: for instance, $\mathrm{PCN}$ who encounter problems in their care for DP or who feel inadequately trained. Because there are no comparable data from non-respondents, this remains unclear. Results might also be influenced by the (varying) level of expertise among PCN: this was not registered. Moreover, due to limited data, no distinction could be made in educational needs based on type of disability of DP receiving care form PCN. However, despite this potential bias, every need for additional education should be addressed as PCN who feel unsure might become reluctant to provide health care services to PCN. ${ }^{[16,18]}$

\subsection{Recommendations}

By identifying opportunities to improve PCN's education, this research is a first step to address the unmet needs of DP. Based on the concerns raised by PCN, an educational program can be implemented. However, to ensure DP are getting the best quality of care, a more structural approach is advised. Focus should be on the pre-qualification train- ing of nurses (and health care professionals in general). ${ }^{[41]}$ There is no necessity to create a new curriculum: elaborating on existing topics, with specific consideration for the needs of patients with a physical and/or intellectual disability can fill in the gaps nurses reported in this research. A project of Bollard et al., aiming at exposing (mental health) nurses to DP by involving these patients in their nurse education, showed to be beneficial to the students as they improved their knowledge of disabilities, as well as their understanding of the need for different ways to communicate with DP. ${ }^{[42]}$ As the pre-qualification training for nurses (in Belgium) will be extended from 3 to 4 years, this would be an opportunity to adjust the curriculum to incorporate more (practical) courses with regard to nursing care needs of DP. An approach similar to Smith et al. can be pursued: teaching students from the point of view of service users and their experiences in trying to get access to necessary health care might be an innovative and intriguing way to educate health care professionals. ${ }^{[33]}$

Moreover, a review of Hemm et al. ${ }^{[25]}$ shows that it is feasible to design a training package that can be deployed in different settings and consequently for different profession groups. Therefore, it would be interesting to develop multidisciplinary, on the job training to tackle common, everyday challenges that professionals, working in residential facilities, as well as PCN, are confronted with in their care for DP. ${ }^{[44]}$

In general, educational programs should include more topics regarding mental health, because mental health has an influence on the physical state of PD and PCN report to be more anxious dealing with behavioral than physical problems. ${ }^{[45-48]}$ One recommendation of World Health Organization is stated to illustrate the importance of mental health care (46): "Certain skills and competencies are required to effectively assess, diagnose, treat, support and refer people with mental disorders; it is essential that primary care workers are adequately prepared and supported in their mental health work". This statement also applies to people with physical and/or mental disability: investing in proper education will equip PCN with the (clinical) knowledge and skills to deliver nursing care to their DP to the best of their abilities.

\section{Conclusions}

Primary care Nurses are important partners in providing primary care to disabled patients (DP). This study provides guidance in identifying PCN's concerns and needs to improve nursing care in both in DP's home as in residential care facilities. To ensure best quality of care for DP, needs of PCN regarding nursing care, communication and education should be addressed. PCN prefer additional education about ways to deal with behavioral problems, functional loss and 
information on supporting measures for DP. These acquired skills might, in turn, resolve the overburdening of informal caregivers.

\section{CONFLiCTS OF InTEREST DisClOSURE}

The authors declare that they have no competing interests.

\section{REFERENCES}

[1] VAPH. Vlaams Agentschap voor Personen met een Handicap [Internet]. [cited 2015 Sep 25]. Available from: http://www . vaph.be/ vlafo/view/nl/204713-en.html

[2] Vlaams Agentschap voor Personen met een Handicap. Zorgregierapport. Gegevens 31 december 2014 - Tweede jaarhelft 2014. 2014.

[3] DG Personen met een handicap. Jaarverslag 2014. In goede handen 2014.

[4] Intrakoop, Verstegen accountants en adviseurs, Marlyse-Research. Jaarverslagenanalyse 2014. Sectorrapport gehandicaptenzorg. Een analyse van de financiële positie, uitgaven, capaciteit en productie van zorgorganisaties actief in de gehandicaptenzorg [Internet]. 2015 Available from: https://www.intrakoop.nl/Organisatie /Nieuws/Documents/IntrakoopJaarverslagenanalyse201 4-Gehandicaptenzorg.pdf

[5] Zorginstituut Nederland. Tabellen toegankelijkheid. Wet langdurige zorg [Tables accessibilty. Act long-term care] [Internet]. iWLZ; 2015. p. 33. Available from: https://www.istandaarden.nl/ storage/app/media/Documentatie/istandaarden/iwlz/W achtlijstinformatieinpdf 2015-Wlz/Tabellen_toeganke lijkheid_Wlz_stand_01-10-2015.pdf

[6] van den Berg M, de Boer D, Gijsen R, et al. Zorgbalans 2014. De prestaties van de Nederlandse gezondheidszorg [Internet]. Rijksinstituut voor Volksgezondheid en Milieu. Bilthoven; 2014. Available from: http://www.gezondheidszorgbalans.nl/dsr esource?type=pdf\&disposition=inline\&objectid=rivmp: 259835

[7] Starfield B, Shi L, Macinko J. Contribution of primary care to health systems and health. Milbank Q. 2005; 83(3): 457-502. PMid:16202000 http://dx.doi.org/10.1111/j.1468-0009. 2005.00409.x

[8] Starfield B. Primary care: An increasingly important contributor to effectiveness, equity, and efficiency of health services. SESPAS report 2012. Gac Sanit. 2012; 26(SUPPL.1): 20-6. PMid:22265645 http://dx.doi.org/10.1016/j.gaceta. 2011.10.009

[9] Maes B, Broekman TG, Došen A, et al. Caregiving burden of families looking after persons with intellectual disability and behavioural or psychiatric problems. J Intellect Disabil Res. 2003; 47(6): 447-55 http://dx.doi.org/10.1046/j.1365-2788.2003.00513.x

[10] Carretero S, Garcés J, Ródenas F, et al. The informal caregiver's burden of dependent people: Theory and empirical review. Arch Gerontol Geriatr. 2009; 49(1): 74-9. PMid:18597866 http://dx.d oi .org/10.1016/j. archger . 2008.05.004

[11] Harkness KI, Tranmer JE. Measurement of the Caregiving Experience in Caregivers of Persons Living With Heart Failure: A Review of Current Instruments. J Card Fail. 2007; 13(7): 577 87. PMid:17826649 http://dx.doi.org/10.1016/j.cardfai 1.2007 .03 .013

[12] Snyder B, Keefe K. The unmet needs of family caregivers for frail and disabled adults. Soc Work Heal Care. 1985; 10(3): 1-14. PMid:3158088. http://dx.doi.org/10.1300/J010v10n03_01

[13] Lennox N, Diggens J, Ugoni A. The general practice care of people with intellectual disability: barriers and solutions. J Intellect Disabil
Res. 1997; 41(5): 380-90. http://dx.doi.org/10.1111/j.136 5-2788.1997.tb00725.x

[14] Baxter H, Lowe K, Houston H, et al. Previously unidentified morbidity in patients with intellectual disability. Br J Gen Pract. 2006; 56(523): 93-8. PMid:16464321.

[15] Lennox N, Van Driel ML, van Dooren K. Supporting primary healthcare professionals to care for people with intellectual disability: a research agenda. J Appl Res Intellect Disabil [Internet]. 2015; 28(1): 33-42. Available from: http://www.ncbi.nlm.nih.gov/pubme $\mathrm{d} / 25530572$

[16] Wilkinson J, Dreyfus D, Cerreto M, et al. "Sometimes I feel overwhelmed": Educational Needs of Family Physicians Caring for People with Intellectual Disability. Intellect Dev Disabil. 2012; 50(3): 243-50. PMid:22731973 http://dx.doi .org/10.1352/1934-9 $556-50.3 .243$

[17] Thornton C. Effective health care for people with learning disabilities: a formal carers' perspective. J Psychiatr Ment Health Nurs [Internet] 1999; 6(5): 383-90. http://dx.doi.org/10.1046/j.1365-285 $0.1999 .00236 . \mathrm{x}$

[18] McDermott S, Moran R, Platt T, et al. Variation in health conditions among groups of adults with disabilities in primary care. J Community Health. 2006; 31(3): 147-59. http://dx.doi.org/10.1007 /s10900-005-9008-y

[19] Cardol M, Dusseljee J, Rijken M, et al. Huisartsenzorg voor mensen met een verstandelijke beperking. Huisarts Wet. 2011; 54(7): 354-8 http://dx.doi.org/10.1007/s12445-011-0177-x

[20] Morrison EH, George V, Mosqueda L. Primary care for adults with physical disabilities: Perceptions from consumer and provider focus groups. Fam Med. 2008; 40(9): 645-51. PMid: 18830840.

[21] Fendall NR. Declaration of Alma-Ata. Lancet. 1978; 2(8103): 1308. http://dx.doi.org/10.1016/S0140-6736 (78) 92066-4

[22] Yee S, Breslin ML. Achieving accessible health care for people with disabilities: Why the ADA is only part of the solution. Disabil Health J [Internet]. Elsevier Inc; 2010; 3(4): 253-61. http: //dx.doi.org/10.1016/j.dhjo.2010.07.006

[23] Felce D, Baxter H, Lowe K, et al. The impact of repeated health checks for adults with intellectual disabilities. J Appl Res Intellect Disabil. 2008; 21(6): 585-96. http://dx.doi.org/10.1111/j.1 $468-3148.2008 .00441 . x$

[24] Scottish Government. Strengthening the commitment. The report of the UK Modernising Learning Disabilities Nursing Review [Internet]. 2012. Available from: http://www.gov.scot/resource/0039 /00391946.pdf

[25] Hemm C, Dagnan D, Meyer TD. Identifying training needs for mainstream healthcare professionals, to prepare them for working with individuals with intellectual disabilities: a systematic review. J Appl Res Intellect Disabil [Internet]. 2015; 28(2): 98-110. Available from: http://doi.wiley.com/10.1111/jar.12117

[26] Elliott RA, Tran T, Taylor SE, et al. Gaps in continuity of medication management during the transition from hospital to residential care: an observational study (MedGap Study). Australas J Ageing [Internet]. 2012 Dec [cited 2014 Jan 30]; 31(4): 247-54. Available from: http://www.ncbi.nlm.nih.gov/pubmed/23252983 
[27] Gillet P, Lange B, Godin J, et al. Position paper: organisation of care for chronic patients in Belgium. 2012. Report No.: 190A.

[28] Gröne O, Garcia-Barbero M. Integrated care: a position paper of the WHO European office for integrated health care services. Int J Integr Care [Internet]. 2001; 1(1): 1-10. Available from: http: //www.ncbi.nlm.nih.gov/pmc/articles/pmc1525335/

[29] Kerr M, Fraser W, Felce D. Primary Health Care for People with a Learning Disability - A keynote review. Br J Learn Disabil [Internet]. 1996; 24(1): 2-8. Available from: http://doi.wiley.com/10.1 111/j.1468-3156.1996.tb00192.x

[30] Chant S, Jenkinson T, Randle J, et al. Communication skills: some problems in nursing education and practice. J Clin Nurs [Internet]. 2002; 11(1): 12-21. Available from: http://www.ncbi.nlm.nih .gov/pubmed/11845748

[31] Olney MF. Communication strategies of adults with severe disabilities: Supporting self-determination. Rehabil Couns Bull [Internet]. 2001; 44(2): 87-94. Available from: http://www. scop us. com/inward/record. url?eid=2-s2.0-0035579685\&par tnerID $=40 \& m d 5=5967 \mathrm{a} 2 \mathrm{fd} 5230239 \mathrm{f} 5 \mathrm{~d} 771 \mathrm{f} 7 \mathrm{c} 045071 \mathrm{c} 8$

[32] Loon J Van, Knibbe J, Hove G Van. From Institutional to Community Support: Consequences for Medical Care. J Appl Res Intellect Disabil. 2005; 6(18): 175-80.

[33] Phillips A, Morrison J, Davis R. General practitioners' educational needs in intellectual disability health. J Intellect Disabil Res. 2004; 48(2): 142-9.

[34] Rimmer JH, Chen MD, Hsieh K. A Conceptual Model for Identifying, Preventing, and Managing Secondary Conditions in People With Disabilities. Phys Ther. 2011; 91(12): 1728-39. PMid:22003160 http://dx.doi.org/10.2522/ptj. 20100410

[35] Emerson E, Kiernan C, Alborz A, et al. The prevalence of challenging behaviors: A total population study. Res Dev Disabil. 2001; 22(1): 7793. http://dx. doi.org/10.1016/S0891-4222(00)00061-5

[36] van Schrojenstein Lantman-de Valk HMJ, Walsh PN. Managing health problems in people with intellectual disabilities. BMJ. 2008; 337(7683): a2507. PMid:19064601.

[37] Bates P, Priest HM, Gibbs M. The education and training needs of learning disability staff in relation to mental health issues. Nurse Educ Pract. 2004; 4(1): 30-8. http://dx.doi .org/10.1016/S14 71-5953(03) 00016-7
[38] NHS Wales. Improving general hospital care of patients who have a learning disability. 2014. Report No.: 22.

[39] National Institute for Health and Clinical Excellence [NICE]. Challenging behaviour and learning disabilities: Prevention and interventions for people with learning disabilities whose behaviour challenges. 2015. Report No.: NG 11.

[40] Sullivan WF, Berg JM, Bradley E, et al. Primary care of adults with developmental disabilities. Can Fam Physician. 2011; 57: 541-53.

[41] Hahn JE. Addressing the need for education: curriculum development for nurses about intellectual and developmental disabilities. Nurs Clin North Am [Internet]. 2003; 38(2): 185-204. Available from: http://linkinghub.elsevier.com/retrieve/p ii/S0029646502001032

[42] Bollard M, Lahiff J, Parkes N. Involving people with learning disabilities in nurse education: towards an inclusive approach. Nurse Educ Today [Internet]. Elsevier Ltd; 2012; 32(2): 173-7. Available from: http://www.ncbi.nlm.nih.gov/pubmed/22036270

[43] Smith P, Ooms A, Marks-Maran D. Active involvement of learning disabilities service users in the development and delivery of a teaching session to pre-registration nurses: Students' perspectives. Nurse Educ Pract. 2016; 16(1): 111-8. PMid:26527058 http://dx.doi.org/10.1016/j.nepr.2015.09.010

[44] Reeves S, Zwarenstein M, Goldman J, et al. Interprofessional education: effects on professional practice and health care outcomes. Cochrane Database Syst Rev. 2008; 1.

[45] Phelan M, Stradins L, Morrison S. Physical health of people with severe mental illness. BMJ. 2001; 322(7284): 443-4. http://dx.d oi.org/10.1136/bmj . 322.7284 .443

[46] World Health Organization World Organization of National Colleges Academies \& Academic Associations of General Practitioners/Family Physicians. Integrating mental health into primary care: a global perspective. 2008.

[47] Kerwick S, Jones R, Mann A, et al. Mental health care training priorities in general practice. $\mathrm{Br} \mathrm{J}$ Gen Pract [ Internet]. 1997; 47(417): 225-7. Available from: http: //www.pubmedcentral.nih.gov/articlerender.fcgi ?artid=1312947\&tool=pmcentrez\&rendertype=abstract

[48] McConkey R, Truesdale M. Reactions of nurses and therapists in mainstream health services to contact with people who have learning disabilities. J Adv Nurs [Internet]. 2000; 32(1): 158-63. Available from: http://www.ncbi.nlm.nih.gov/pubmed/10886447 